\title{
PENYULUHAN PENANGANAN HAMA TIKUS DI DESA SUKARATU DAN INDERAJAYA, KECAMATAN SUKARATU KABUPATEN TASIKMALAYA
}

Bari, I. N. Dan Natawigena, W.D.

Fakultas Pertanian, Universitas Padjadjaran

E-mail: daradjat327@gmail.com

\begin{abstract}
ABSTRAK
Penyuluhan tentang Penyuluhan Penanganan Hama Tikus Di Desa Sukaratu dan Inderajaya, Kecamatan Sukaratu, Kabupaten Tasikmalaya telah dilaksanakan dalam rangka Pengabdian kepada Masyarakat. Kegiatan ini dilaksanakan selama 4 bulan, yaitu dari bulan Januari hingga April 2014. Tahapan kegiatan meliputi (1) pelaksanaan Training of Trainer bagi mahasiswa peserta Kuliah Kerja Nyata, (2) penelusuran data sekunder berupa profil dan monografi lokasi, (3) penelusuran data primer dengan alat kuestioner, dan (4) pelaksanaan penyuluhan. Kegiatan penyuluhan ini melibatkan petani, mahasiswa peserta KKNM, dan aparat pemerintahan terkait. Dalam pelaksanaan penyuluhan ini dilakukan pengenalan berbagai jenis tikus, biologi, dan pengendaliannya pada agroekosistem sawah. Dampak yang terukur setelah pelaksanaan kegiatan ini adalah bertambahnya pengetahuan petani dalam hal mengenal jenis dan pengendalian tikus pada pertanaman padi.
\end{abstract}

Kata kunci: Hama Tikus, Tanaman padi, Penyuluhan

\section{ABSTRACT}

Extention about rat controls on Rice field in Sukaratu and Inderajaya Village, Sukaratu District, Tasikmalaya Resident, West Java has been done in the framework of Community Service. The event was held for four months, from January to April 2014. Phases of activity include (1) Training of Trainers for students who were participating in Field Work Experience, (2) tracing of secondary data and monographs profile, (3) tracing of primary data by questionnaires, and (4) extention program. The activities included farmers, students and relevant government officials. Measurable impact after the implementation of this activity was increased knowledge of farmers in terms of knowing the rat controls in the rice field.

Key words: rat, the rice crop, extention

\section{PENDAHULUAN}

Tasikmalaya merupakan salah satu sentra produksi beras di Jawa Barat. Beras Tasikmalaya telah berhasil menembus pasar ekspor ke beberapa Negara, yaitu diantaranya Amerika, Uni Eropa, Malaysia, Singapura dan Hongkong. Total produksi padi organik yang dihasilkan petani Tasikmalaya, $80 \%$ ditujukan untuk pasar ekspor, hanya 20\% untuk pasar lokal, sementara sisa produksi dimanfaatkan pula untuk konsumsi sendiri bagi petani (DEPTAN, 2014).

Tasikmalaya memiliki 49.460 ha lahan sawah dengan total luas produksi 855.197 ton/tahun (BPS, 2013). Kondisi areal persawahan yang sangat luas di Kabupaten Tasikmalaya tersebut secara tidak langsung memberikan daya dukung lingkungan serta daya dukung pakan yang kondusif bagi tingginya tingkat populasi tikus di kawasan tersebut.
Tikus menempati relung ekologi yang sama dengan manusia. Setiap makanan yang dapat dikonsumsi oleh manusia maka dapat pula dikonsumsi oleh tikus. Begitu pula dengan tempat, setiap lokasi yang dapat didiami oleh manusia maka tikus dapat tumbuh dan berkembang dengan baik di lokasi tersebut. Oleh karena itu dari sudut pandang antroposentris, tikus dikategorikan sebagai hama yang keberadaannya dapat menimbulkan kerugian bagi manusia. Tikus merupakan hama multisektoral. Di dunia kesehatan, tikus dikenal sebagai pembawa (carrier) dari berbagai penyakit yang dapat menular kepada manusia. Di dunia industri, tikus merupakan sumber kontaminan yang dapat mengurangi kualitas dan kuantitas produksi, sementara di dunia pertanian, tikus merupakan hama yang menyerang berbagai komoditas pada berbagai stadia tanaman.

Pemahaman petani mengenai strategi pengendalian tikus yang baik akan meningkatkan tingkat keberhasilan, efisiensi dan efektifitas pelaksanaanya. Oleh karena itu kegiatan sosialisasi ini perlu dilakukan sebagai upaya meningkatkan produktifitas lahan pertanian dan tingkat kesejahteraan petani.

Berdasarkan analisis situasi di atas, maka dapat dirumuskan bahwa permasalahan yang dihadapi dalam kegiatan Pengabdian kepada masyarakat adalah diperlukannya sosialisasi pengendalian hama tikus, yaitu berupa kegiatan "Penyuluhan Penanganan Hama Tikus di Desa Sukaratu dan Inderajaya, Kecamatan. Sukaratu, Kabupaten Tasikmalaya"

\section{HASIL DAN PEMBAHASAN}

Rangkaian kegiatan Kursus Tani Pengendalian Hama Tikus Terpadu di Desa Sukaratu dan Desa Inderajaya Kecamatan Sukaratu Kabupaten Tasikmalaya terdiri dari 3 tahapan, yaitu (1) Tahapan Persiapan, (2) Perlaksanaan Kursus Tani Pengendalian Hama Tikus Terpadu dan (3) Tahapan Evaluasi. Masing-masing tahapan diuraikan sebagai berikut:

\section{A. Tahapan Persiapan}

I. Training of Trainer Mahasiswa Peserta KKMM. Kegiatan Training of Trainer (TOT) dilaksanakan dengan tujuan untuk menciptakan sinergisme antara Program Pengabadian kepada Masyarakat yang dilaksanakan oleh Dosen dengan program Kuliah Kerja Nyata yang dijalankan oleh Mahasiswa. Memberi Penyuluhan Pengendalian Hama Tikus Terpadu, dan (3) pembahasan Metode FGD dalam pelaksanaan Kursus Tani Pengendalian Hama Tikus Terpadu.

II. Penelusuran data sekunder. Penelusuran data sekunder dilakukan dengan tujuan untuk mengetahui gambaran awal kondisi umum dari 
wilayah sasaran tempat pelaksanaan kegiatan Pengambdian kepada Masyarakat, khususnya mengenai gambaran kondisi pertanian di lokasi tersebut. Data-data sekunder yang ditelusuri tersebut adalah berupa profil/monografi/programa yang berada di lingkungan administarsi desa, kecamatan dan kantor Badan Penyuluh Pertanian (BPP) setempat. Kegiatan ini dilakukan pada tanggal 7 Januari 2014.

III. Penelusuran data primer (Questionering). Penelusuran data primer dengan menggunakan media kuestioner dilakukan dengan tujuan untuk menggali informasi awal dari petani responden calon peserta kursus tani yang akan dilaksanakan kemudian hari, sehingga metoda dan materi kegiatan dapat dipersiapkan lebih efektif dan efisien, sesuai dengan kebutuhan petani peserta. Sasaran adalah para petani yang memiliki kriteria sebagai berikut:

a. Memiliki atau mengelola lahan persawahan.

b. Warga Desa Sukaratu dan Desa Inderajaya, Kecamatan Inderajaya, Kabupaten Tasikmalaya.

c. Bersedia menjadi peserta 'Kursus Tani Pengendalian Hama Tikus Terpadu'
Kegiatan ini dilaksanakan pada tanggal 14 sampai dengan tanggal 21 Januari 2013 dengan cara mengunjugi kediaman petani yang tersebar di wilayah Desa Sukaratu dan Desa Inderajaya, Kecamatan Inderajaya, Kabupaten Tasikmalaya. Adapun pelaksana atau enumerator dari kuestioner adalah mahasiswa peserta KKNM yang telah mengikuti TOT.

\section{Perlaksanaan Kegiatan Penyuluhan}

Pelaksanaan "Penyuluhan Pengendalian Hama Tikus di Desa Sukaratu dan Desa Inderajaya Kecamatan Sukaratu Kabupaten Tasikmalaya" merupakan pokok acara dalam seluruh rangkaian kegiatan yang dilaksanakan. Kegiatan ini dilaksanakan pada tanggal 31 Januari

2014 di balai Desa Sukaratu. Total peserta petani yang hadir dalam kegiatan ini adalah sebanyak 30 orang yang terdiri dari petani reseponden yang telah diwawancarai oleh mahasiswa (enumerator) serta pihak berbagai terkait.

Kegiatan Kursus Tani Pengendalian Hama Tikus Terpadu ini dilakukan dengan cara Ceramah dan pemutaran video yang berkaitan dengan strategi pengendalian tikus sawah.
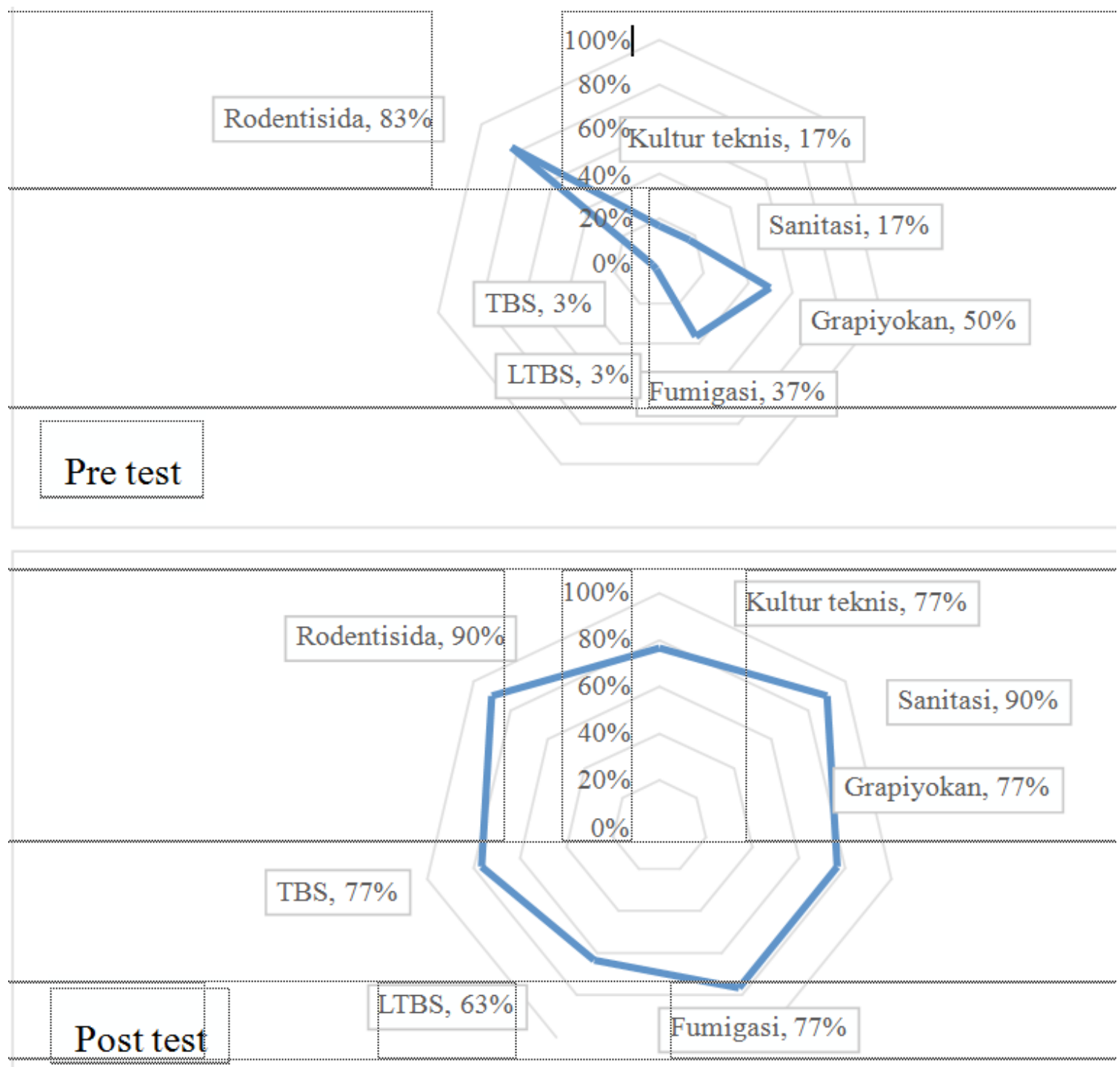

Diagram 1. Hasil pre \& post Test 
Hasil pre \& post Test pada Diagram di atas menunjukan bahwa telah terjadi peningkatan wawasan peserta kursus tani mengenai berbagai komponen pengendalian tikus sawah pada areal pertanaman padi.

\section{Faktor Pendorong dan Penghambat}

Faktor-faktor pendorong kegiatan antara lain:

1. terdapatnya wadah kelompok tani sehingga memudahkan dalam berkoordinasi.

2. daerah Kecamatan Sukaratu merupakan salah satu daerah lumbung padi di KabupatenTasikmalaya.

3. dukungan Aparatur pemerintahan tingkat desa yang sangat tinggi dan sehingga dapat turut memfasilitasi kegiatan yang direncanakan

4. pada periode musim tertentu, petani padi sering kali bermasalah dengan hama tikus, sehingga pelatihan yang direncanakan mendapat antusiasme yang cukup tinggi di kalangan petani

Faktor-faktor penghambat kegiatan ini antara lain:

1. musim penghujan yang tengah terjadi pada periode pelaksanaan pengabdian mengakibatkan serangan tikus tidak terjadi di lokasi.

2. waktu pelaksanaan pengabdian yang hanya 4 bulan mengakibatkan kegiatan pendampingan tidak dapat dilaksanakan.

\section{SIMPULAN}

Kegiatan penyuluhan telah dilaksanakan dengan baik di Desa Sukaratu dan Inderajaya, Kecamatan
Sukaratu, Kabupaten Tasikmalaya melalui pengenalan berbagai jenis predator, parasitoid, entomopatogen dan mikroba antagonis yang berperan sebagai musuh alami di agroekosistem sawah. Identifikasi organisme penganggu tanaman pada padi telah demontrasikan di dalam kegiatan penyuluhan ini. Dampak yang terukur setelah pelaksanaan kegiatan ini adalah bertambahnya pengetahuan petani dalam hal mengenal jenis dan peranan musuh alami pada pertanaman padi.

\section{DAFTAR PUSTAKA}

Badan Litbang Pertanian. (2011). Inovasi Teknologi Pengendalian Tikus. (Sudarmaji \& N. Herawati, Eds.) (Edisi 17-2., pp. 1-16). Jakarta Selatan: Sinar Tani.

Balai Besar Penelitian Tanaman Padi. (2009). Tikus. Bank Pengetahuan Padi Indonesia (pp. 14 16). Sukamandi: Kementrian Pertanian. Retrieved from http://www.pustaka- deptan. go.id

BPS. (2013). Kabupaten Tasikmalaya dalam Angka 2011. Tasikmalaya. www.cianjurkab.go.id. (2012). Fokus Pembangunan Kabupaten Cianjur. Dinas Perhubungan Komunikasi dan Informatika Kabupaten Cianjur. Retrieved from http://www.cianjurkab.go.id/Content Nomor_Menu_22_3.html 